\title{
РЕЗУЛЬТАТЫ ИССЛЕДОВАНИЯ ХИМИЧЕСКОГО СОСТАВА ПОДЗЕМНЫХ ВОД В ХИБИНСКОМ МАССИВЕ И ЕГО ОКРЕСТНОСТЯХ: НОВЫЕ ДАННЫЕ
}

\section{Мазухина С.И. ${ }^{1}$, Пожиленко В.И.ㄹ, Дрогобужская С.В ${ }^{3 .,}$ Сандимиров С.С ${ }^{4}$}

${ }^{1}$ Горный институт КНЦ РАН, simazukhina@mail.ru

${ }^{2}$ Геологический институт КНЦ РАН, pozhil@geoksc.apatity.ru

${ }^{3}$ Институт химии и технологии редких элементов и минерального сырья им. И.В. Тананаева КНЦ РАН, Drogo_sv@chemy.kolasc.net.ru

${ }^{4}$ Научно-исследовательский иентр медико-биологических проблем адаптации человека в Арктике КНЦ PAH, sand1966@ramglrt.ru

Исследователи России и зарубежных стран, занимающиеся медико-экологической оценкой загрязнения питьевой воды, указывают на связь здоровья населения с химическим составом подземных вод и антропогенных включений. На формирование химического состава подземных вод оказывают многочисленные природные и антропогенные факторы, в том числе химические составы пород и поверхностных вод. В работе рассмотрен комплекс геологических, физико-химических и медико-экологических задач. В настоящее время качество питьевых вод оценивается по СанПину (сравнение с ПДК элементов или соединений), но в работе [5] указано на необходимость учитывать еще и соотношение некоторых элементов.

Целью работы является обнаружение изменения химического состава природных вод, формирующихся в пределах Хибинского массива и его ближайшего обрамления, в зависимости от состава пород области водосбора и от антропогенного влияния с помощью физико-химического моделирования (программный комплекс (ПК) «Селектор») и современных прецизионных методов анализа. Для исследований был произведен отбор проб подземных вод из источников, пользующиеся популярностью у жителей Апатитско-Кировского района (точки 1-5), поверхностных и подземных вод в районе реки Малая Белая (точки 6-8), а также подземных вод из скважин водозабора «Предгорный» в р-не п. Коашва Кировского района (точки 9-13) и водозабора «Центральный» в р-не г. Кировска (точки 14-19) (рис. 1).

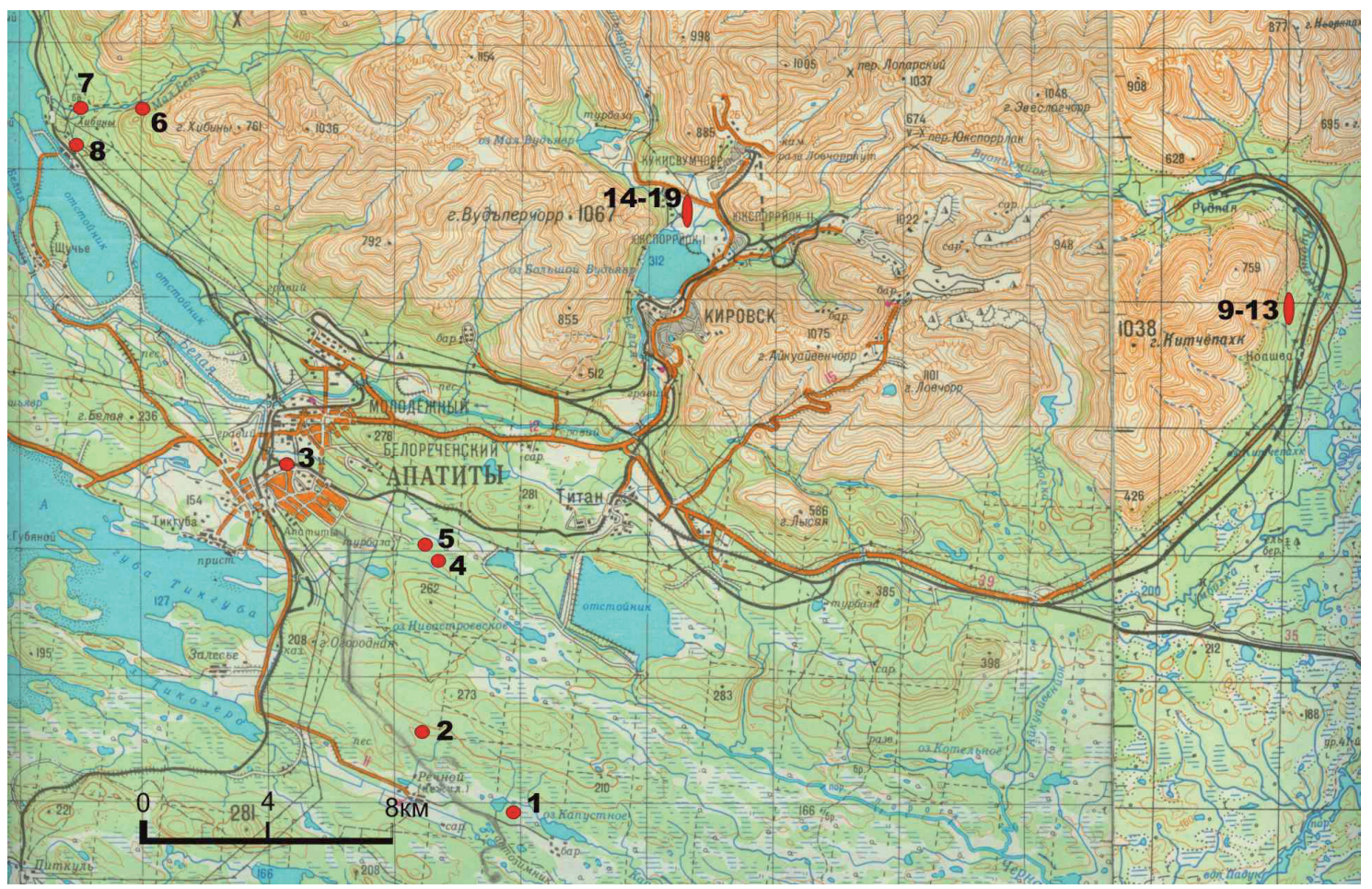

Рис. 1. Расположение на топографической карте точек (красные кружки) и участков (красные овалы) отбора проб воды из родников и скважин на территории Кировского и Апатитского районов. 
Для расчета химических равновесий авторы использовали ПК «Селектор», в его последней модификации [8]. Применительно к исследуемым гидрохимическим системам создана базовая модель «вода-порода-газ-органическое вещество», включая широкий спектр независимых компонентов (37) и до 435 компонентов водного раствора (включая растворенные газы, большое число потенциально возможных в равновесии твердых фаз (180) и 76 газовых компонентов. Необходимая термодинамическая информация взята из встроенных в ПК баз данных.

Полный гидрохимический анализ показал присутствие в водах таких элементов как уран, молибден, серебро, барий, что пополнило базу данных химического состава подземных вод. Для физико-химического моделирования были сделаны выборки химических анализов наиболее распространенных пород, слагающих юго-восточную часть Хибинского массива, как основную область водосбора. Анализ результатов, полученных с помощью моделирования взаимодействия «вода-порода» и аналитических данных, позволил отделить породное влияние от антропогенного, природный химический состав вод от состава профильтрованных рудничных (антропогенных). Установлено, что на формирование химического состава подземных вод водозабора «Предгорный» оказывают влияние химические составы пород и поверхностных вод, содержащие кислород, нитраты и хлор, которые влияют на значения рН (уменьшая их) и на формы миграции алюминия, марганца, железа и других элементов.

\section{Водозабор «Центральный»}

Постоянно действующий водозабор «Центральный» снабжает питьевой водой население г. Кировска с 1977 года. В 1985-1988 гг. было установлено, что практически во всех эксплуатируемых скважинах водозабора содержание алюминия превышает значения ПДК (0.5 мг/л). Содержание алюминия в воде одной и той же скважины составляет от 0.05 до 1.48 мг/л. Комплекс работ, выполненный сотрудниками МГРЭ в долинах приозерных низменностей озер Малый и Большой Вудъявр в 1991-1998 гг., не позволил установить причину природного некондиционного качества подземных вод по Al и рН [7]. Результаты исследования вод водозабора «Центральный» 2017 г. показывают, что в четырёх скважинах наблюдаются высокие значения $\mathrm{pH}$, концентрации $\mathrm{Al}, \mathrm{Na}, \mathrm{HCO}_{3}^{-}$и $\mathrm{Eh}<0$ (табл.1, Б - водозабор «Болотный», водами которого разбавляют воды из скважин водозабора «Центральный»). Ранее, в работе [2], была дан прогноз подобной ситуации, а в работе [1] оценен возраст вод водозабора. Иными словами - усиленная эксплуатация водоносных скважин водозабора «Центральный» приводит к «подсосу» некондиционных древних вод.

Таблица 1. Результаты анализа состава подземных вод водозабора «Центральный».

\begin{tabular}{|c|c|c|c|c|c|c|}
\hline \multirow{2}{*}{ Параметры } & \multicolumn{5}{|c|}{ Концентрации некоторых компонентов, мг/л } \\
\cline { 2 - 7 } & Скв. 10 & Скв. 9 & Скв. 7 & Скв. 3 & Скв. 5 & Б \\
\hline $\mathrm{B}$ & 0.0163 & 0.0169 & 0.015 & 0.015 & 0.015 & 0.013 \\
\hline $\mathrm{Na}$ & 29.2 & 21.8 & 11.5 & 13.1 & 17.5 & 5.74 \\
\hline $\mathrm{Mg}$ & 0.042 & 0.025 & 0.002 & $<0.0001$ & 0.0083 & 0.081 \\
\hline $\mathrm{Al}$ & 0.35 & 0.84 & 0.97 & 1.07 & 0.89 & 0.085 \\
\hline $\mathrm{Si}$ & 1.90 & 1.65 & 1.91 & 1.76 & 1.76 & 2.86 \\
\hline $\mathrm{P}$ & 0.023 & 0.029 & 0.019 & 0.032 & 0.015 & 0.014 \\
\hline $\mathrm{K}$ & 4.15 & 2.40 & 1.19 & 1.17 & 1.70 & 1.66 \\
\hline $\mathrm{Ca}$ & 0.075 & 0.24 & 0.027 & 0.0079 & 0.113 & 0.89 \\
\hline $\mathrm{HCO}{ }^{-}$ & 46.2 & 40.7 & 26.3 & 30.9 & 37.7 & 17.6 \\
\hline $\mathrm{pH}$ & 8.97 & 9.39 & 9.63 & 9.57 & 9.46 & 7.72 \\
\hline $\mathrm{Eh}, \mathrm{mB}$ & -108 & -130.4 & -145.9 & -141.8 & -134.6 & -36.8 \\
\hline
\end{tabular}

Кондиционность этих вод может быть достигнута специальной водоподготовкой (разбавлением богатыми кислородом водами, созданием отстойников, взаимодействием этих вод с геохимическими барьерами и т.д.). 
Родники, используемые жителями г. Апатиты как источник питьевой воды

Таблица 2. Аналитические данные (АД) и результаты моделирования (РМ) вод родников и подземных вод в окрестностях г. Апатиты $\left(\mathrm{T}=3^{\circ} \mathrm{C}, \mathrm{P}=1\right.$ бар, мг/л).

\begin{tabular}{|c|c|c|c|c|c|c|}
\hline \multirow{2}{*}{ Параметр } & \multicolumn{2}{|c|}{ Родник 1} & \multicolumn{2}{|c|}{ Родник 3} & \multicolumn{2}{|c|}{ Родник 5} \\
\hline & А.Д & P.M. & А.Д & P.M. & А.Д & P.M. \\
\hline $\mathrm{pH}$ & 8.22 & 8.50 & 7.03 & 7.13 & 8.03 & 8.28 \\
\hline Eh. B & & 0.748 & & -0.205 & & 0.765 \\
\hline $\mathrm{Ca}$ & 34.3 & $3.24 \mathrm{E}+01$ & 46.8 & $4.48 \mathrm{E}+01$ & 22.3 & $2.16 \mathrm{E}+01$ \\
\hline $\mathrm{Na}$ & 6.01 & 6.00 & 24.9 & $2.49 \mathrm{E}+01$ & 5.15 & 5.13 \\
\hline $\mathrm{K}$ & 4.19 & 4.19 & 3.14 & 3.14 & 0.79 & 7.87E-01 \\
\hline $\mathrm{Mg}$ & 4.98 & 4.76 & 6.50 & 6.24 & 1.32 & 1.28 \\
\hline $\mathrm{Sr}^{2+}$ & 0.188 & $1.83 \mathrm{E}-01$ & 0.17 & $1.64 \mathrm{E}-01$ & 0.059 & 5.83E-02 \\
\hline $\mathrm{Fe}$ & 0.076 & 7.64E-02 & 0.15 & $1.46 \mathrm{E}-01$ & 0.67 & $6.65 \mathrm{E}-01$ \\
\hline $\mathrm{Fe}^{2+}$ & - & $9.05 \mathrm{E}-14$ & - & $1.46 \mathrm{E}-01$ & - & $1.79 \mathrm{E}-12$ \\
\hline $\mathrm{Fe}(\mathrm{OH})_{3}$ & - & $1.00 \mathrm{E}-02$ & - & 4.32E-12 & - & $8.68 \mathrm{E}-02$ \\
\hline $\mathrm{Fe}(\mathrm{OH})_{4}^{-}$ & - & $6.36 \mathrm{E}-03$ & - & $1.19 \mathrm{E}-13$ & - & $3.28 \mathrm{E}-02$ \\
\hline $\mathrm{FeSO}_{4}$ & - & $1.76 \mathrm{E}-13$ & - & 4.68E-04 & - & $3.06 \mathrm{E}-14$ \\
\hline $\mathrm{FeO}_{2}^{-}$ & - & $2.26 \mathrm{E}-03$ & - & $4.24 \mathrm{E}-14$ & - & $1.17 \mathrm{E}-02$ \\
\hline $\mathrm{HFeO}_{2}$ & - & $1.01 \mathrm{E}-01$ & - & $4.37 \mathrm{E}-11$ & - & $8.79 \mathrm{E}-01$ \\
\hline $\mathrm{FeO}^{+}$ & - & 4.03E-03 & - & $4.14 \mathrm{E}-11$ & - & $5.82 \mathrm{E}-02$ \\
\hline $\mathrm{FeOH}^{+}$ & - & $3.58 \mathrm{E}-15$ & - & $2.28 \mathrm{E}-04$ & - & 4.13E-14 \\
\hline $\mathrm{Mn}$ & 0.0023 & $2.29 \mathrm{E}-03$ & 0.032 & $3.23 \mathrm{E}-02$ & 0.144 & $1.44 \mathrm{E}-01$ \\
\hline $\mathrm{Mn}^{2+}$ & & $2.28 \mathrm{E}-03$ & & $3.23 \mathrm{E}-02$ & & 1.44E-01 \\
\hline $\mathrm{MnSO}_{4}$ & & $2.56 \mathrm{E}-05$ & & 7.12E-05 & & $1.69 \mathrm{E}-03$ \\
\hline $\mathrm{MnOH}+$ & & $3.11 \mathrm{E}-06$ & & $1.85 \mathrm{E}-06$ & & $1.22 \mathrm{E}-04$ \\
\hline $\mathrm{MnF}^{+}$ & & $3.71 \mathrm{E}-08$ & & - & & $2.38 \mathrm{E}-06$ \\
\hline $\mathrm{MnCl}^{+}$ & & 2.29E-08 & & - & & $2.81 \mathrm{E}-07$ \\
\hline $\mathrm{P}$ & & $5.50 \mathrm{E}-03$ & 0.015 & $1.53 \mathrm{E}-02$ & 0.0094 & $9.40 \mathrm{E}-03$ \\
\hline $\mathrm{NO}_{3}^{-}$ & 0.67 & $6.69 \mathrm{E}-01$ & & 6.20 & 0.62 & $3.98 \mathrm{E}-01$ \\
\hline $\mathrm{HCO}_{3}-$ & $104.4 \pm 11.5$ & $1.34 \mathrm{E}+02$ & $155 \pm 17.1$ & $2.28 \mathrm{E}+02$ & $64.6 \pm 7.1$ & $7.70 \mathrm{E}+01$ \\
\hline $\mathrm{O}_{2}$ & & 3.23 & & - & & 7.93 \\
\hline $\mathrm{CO}_{2}$ & & 1.03 & & $4.03 \mathrm{E}+01$ & & $9.93 \mathrm{E}-01$ \\
\hline $\mathrm{H}_{2} \mathrm{~S}$ & & & & 5.61 & & \\
\hline $\mathrm{CH}_{4}$ & & & & 7.81E-04 & & \\
\hline $\mathrm{HS}^{-}$ & & & & 3.35 & & \\
\hline $\mathrm{Ag}$ & 0.0016 & $1.64 \mathrm{E}-03$ & 0.0034 & 3.44E-03 & 0.0034 & $3.36 \mathrm{E}-03$ \\
\hline $\mathrm{Ag}^{+}$ & & $3.97 \mathrm{E}-11$ & & $1.92 \mathrm{E}-14$ & & $1.23 \mathrm{E}-10$ \\
\hline $\mathrm{AgNO}_{3}$ & & $2.45 \mathrm{E}-03$ & & $1.06 \mathrm{E}-05$ & & $4.57 \mathrm{E}-03$ \\
\hline $\mathrm{Ag}(\mathrm{HS})_{2}^{-}$ & & & & $5.53 \mathrm{E}-03$ & & \\
\hline $\mathrm{U}$ & 0.0015 & $1.51 \mathrm{E}-03$ & 0.00049 & 4.93E-04 & 0.00011 & $1.16 \mathrm{E}-04$ \\
\hline $\mathrm{HUO}_{4}^{-}$ & & $3.14 \mathrm{E}-04$ & & $3.62 \mathrm{E}-15$ & & $1.53 \mathrm{E}-05$ \\
\hline $\mathrm{UO}_{3}$ & & $1.52 \mathrm{E}-03$ & & $4.03 \mathrm{E}-13$ & & $1.25 \mathrm{E}-04$ \\
\hline $\mathrm{UO}_{2} \mathrm{OH}^{+}$ & & $7.84 \mathrm{E}-07$ & & $4.95 \mathrm{E}-15$ & & $1.07 \mathrm{E}-07$ \\
\hline $\mathrm{UO}_{2}$ & & & & $5.59 \mathrm{E}-04$ & & \\
\hline $\mathrm{Ba}^{2+}$ & 0.0181 & $1.80 \mathrm{E}-02$ & 0.0196 & $1.96 \mathrm{E}-02$ & 0.0048 & $4.75 \mathrm{E}-03$ \\
\hline $\begin{array}{l}\mathrm{BaCO}_{3} \\
\text { С. моль }\end{array}$ & & $1.26 \mathrm{E}-04$ & & $\begin{array}{l}9.17 \mathrm{E}-06 \\
5.10\end{array}$ & & $1.16 \mathrm{E}-05$ \\
\hline
\end{tabular}


В исследуемых источниках, расположенных в окрестностях г. Апатиты (рис. 1), содержащих кислород, железо находится в трехвалентной форме. Самые высокие концентрации кальция, натрия, нитрата и гидрокарбоната - в водах родника, расположенного, практически, в г. Апатиты, за железной дорогой (табл. 2, родник 3). Это указывает на антропогенное загрязнение этих вод: воды насыщены углеводородами, содержат сероводород и метан. В бальнеологических железистых водах железо находится, в основном, в двухвалентной форме. Формы миграции и других поливалентных элементов (уран, марганец и др.) зависят от окислительно-восстановительных условий, что, видимо, будет оказывать влияние на здоровье населения. В работе [9] особое внимание уделено сведениям о связи наиболее распространенных и опасных онкологических заболеваний с составом используемых подземных вод, загрязненных химическими веществами. Риск повышения уровня этих заболеваний во многих исследованиях связывают с обнаружением в подземных водоисточниках канцерогенных органических соединений антропогенного происхождения. Согласно проведенным исследованиям, этот родник необходимо взять под особый контроль.

К категории «относительно нормальная экологическая ситуация» относится ситуация, когда соотношение $\mathrm{Ca} / \mathrm{Sr}>100$ [5]. Соотношения $\mathrm{Ca} / \mathrm{Sr}$ в указанных источниках составляют $182,275,376$, соответственно, т.е. в трех источниках соотношение превышает 100 (табл. 2). Предварительный анализ результатов показывает, что из обследованных объектов вода наилучшего качества в напорной скважине, расположенной в районе 10-го км по дороге «Апатиты-аэропорт Хибины».

\section{Поверхностные и подземные воды в долине р. Малая Белая}

В 2006-2008 гг. в долине р. Малой Белой для водоснабжения г. Апатиты и его пригородов были проведены независимые экспертные исследования при участии экспертов Геологической службы Финляндии (GTK) и Горного института Кольского научного центра PAH $[3,4]$.

Анализ результатов мониторинга вод колодца, поверхностных и подземных вод долины реки Малой Белой показал, что самые низкие концентрации по кальцию, магнию, стронцию, железу, серебру и барию содержатся в скважине 1 долины реки Малая Белая (точка 6 на рис. 1), при высоких показателях рН (больше 9) и концентрации фтора (4.5 мг/л). Концентрации всех элементов вод реки Малая Белая и подземных вод из скважины входят в интервалы концентраций чистых поверхностных вод по результатам обследования в 2001 г и результатам моделирования взаимодействия «вода-порода» [6, стр. 60-66]. Относительно высокие концентрации кальция, натрия, магния, калия, нитрата и гидрокарбоната позволяют сделать вывод о загрязнении вод точки 8 (рис. 1). Соотношения $\mathrm{Ca} / \mathrm{Sr}$ в указанных объектах составляют $56,19,38$ соответственно, т.е. во всех объектах ниже 100. Соотношения Са/Р составляют 518, 91, 68 соответственно. Такая ситуация, скорее всего, должна быть отнесена к категории «чрезвычайной экологической ситуации» [5].

Таким образом, показано, что уже в подземных (чистых) водах выявленные соотношения $\mathrm{Ca} / \mathrm{P}$ и $\mathrm{Ca} / \mathrm{Sr}$ могут приводить к болезням костей у населения. Результаты исследования 2017 г. приводят к выводу о необходимости проведения дополнительных исследований указанных районов.

Исследование выполнено при финансовой поддержке РФФИ и Министерства образования и науки Мурманской области в рамках научного проекта №17-45-510640 «Геохимическая оценка подземных вод Хибинского массива (возраст и идентификация происхождения подземных вод, химический состав, формы миграции элементов)».

\section{Литература}

1. Гудков А.В., Каменский И.Л., Мелихова Г.С., Скиба В.И., Токарев И.В., Толстихин И.Н. Тритийгелий-3 метод и его применение для датирования подземных вод (на примере Кировского горнопромышленного района, Мурманская область) // Геохимия. 2014. № 5. С. 1-8.

2. Калинников В.Т., Мазухина С.И.. Максимова В.В., Маслобоев В.А., Чудненко К.В. Физикохимические факторы некондиционности химического состава природных вод Хибинского массива // ДАН. 2014. Т. 458. № 5. C. 551-554.

3. Конухин В.П., А.А. Козырев, А.О., Орлов, Ю.Г. Смирнов. Исследование подземных источников для города Апатиты // Экология и промышленность России. 2010. С. 52-54. 
4. Конухин В.П., Козырев А.А., Орлов А.О., Смирнов Ю.Г. Исследование подземных источников для водоснабжения городов Заполярья экологически чистой водой на примере города Апатиты // Арктика: Экология и экономика. 2012. № 2 (6). С. 58-65.

5. Кравченко С.М. Кальций-фосфорные отношения в геохимических ландшафтах и его влияние на здоровье человека // Геоэкология. 1998. № 1. С. 30-36.

6. Мазухина С.И. Формирование поверхностных и подземных вод Хибинского горного массива Апатиты: изд. КНЦ РАН. 2012. 173 с.

7. Отчет о результатах разведки подземных вод для водоснабжения г. Кировска Мурманской области за 1991-1998 гг. (с подсчетом запасов по состоянию на 01.01.1999 г.) (отв. исп. Н.А. Максимова) // Фонды Комитета природных ресурсов по Мурманской области. Мурманск. 1999.

8. Чудненко К.В. Термодинамическое моделирование в геохимии: теория, алгоритмы, программное обеспечение приложения. Новосибирск: Академ. изд-во «Гео». 2010. 287 с.

9. Эльпинер Л.И., Зекцер И.С. Междисциплинарный подход к оценке использования подземных вод для питьевых целей // Водные ресурсы. 1999. Т. 26. № 4. С. 389-39. 